\title{
Hubungan Pengetahuan Keluarga dan Perilaku Keluarga pada Penanganan Awal Kejadian Stroke
}

\author{
Marina T. N Rosmary ${ }^{1}$, Fitria Handayani ${ }^{{ }^{*}}$ \\ ${ }^{1}$ Departemen Ilmu Keperawatan, Fakultas Kedokteran, Universitas Diponegoro, Semarang, Indonesia
}

fitriaha@yahoo.co.id

\begin{abstract}
Introduction: Early intervention of stroke would be reduced mortality and risk of disability. Early intervention was supported by the knowledge of risk factors and early symptoms of stroke. This study was aimed to determine the relationship between family knowledge and behavior in the initial treatment of stroke events.

Methods: This study used a correlational descriptive design with cross-sectional approach. The researchers employed a non-probability sampling i.e. accidental sampling. The study was conducted at a hospital in Semarang in May 2019. The respondents were 77 families of patients during the stroke. The knowledge tool used the Stroke Recognition Questionnaire (SRQ) consisting of 30 questions and a behavioral questionnaire involving nine questions. Data analysis used Spearman Rank.

Results: The result of bivariate analysis indicates there is a correlation between family knowledge and behavior with the value $P=0.000$ and $r=0.83$.

Conclusion: The study concluded there was a correlation between knowledge and behavior. Correlation between the two variables was strong and indicated the positive direction of correlation which the higher of knowledge influenced the better of Family behavior. Nursing interventions needs to be developed to increase knowledge about the risk factors and early symptoms of stroke and management at home at the stroke outbreak.
\end{abstract}

Keywords: Behavior, Early Treatment, Knowledge, Stroke.

\begin{abstract}
Abstrak
Pendahuluan: Penanganan awal stroke yang cepat dan tepat dapat mengurangi angka kematian dan risiko kecacatan. Hal ini didukung oleh adanya pengetahuan tentang faktor resiko dan gejala awal stroke. Penelitian ini bertujuan untuk mengetahui hubungan antara pengetahuan keluarga dengan perilaku keluarga pada penanganan awal kejadian stroke.

Metode: Penelitian ini menggunakan rancangan deskriptif korelasional dengan pendekatan crosssectional. Teknik sampling yang digunakan yaitu non probability sampling jenis accidental sampling. Penelitian dilaksanakan di sebuah rumah sakit di Semarang pada bulan Mei 2019. Responden yang diteliti sebanyak 77 orang yaitu keluarga dari pasien saat serangan stroke berlangsung. Alat penelitian ini berupa kuesioner. Kuesioner pengetahuan menggunakan Stroke Recognition Questionnaire (SRQ) terdiri dari 30 pertanyaan dan kuesioner perilaku terdiri dari 9 pertanyaan. Analisis data menggunakan Spearman Rank.
\end{abstract}

Hasil: Hasil analisis bivariat menunjukkan ada hubungan antara pengetahuan keluarga dengan perilaku keluarga dengan nilai $p=0,000$ dan $r=0,839$.

Kesimpulan: Kesimpulan dari penelitian ini adalah terdapat hubungan antara pengetahuan dan perilaku dengan kekuatan korelasi antar kedua variabel kuat dan menunjukkan arah korelasi positif dimana semakin tinggi pengetahuan maka semakin baik perilaku keluarga. Intervensi keperawatan 
perlu dikembangkan untuk meningkatkan pengetahuan tentang faktor risiko dan gejala awal stroke serta penatalaksanaan di rumah saat serangan.

Kata kunci: Penanganan Awal, Pengetahuan, Perilaku, Stroke.

\section{PENDAHULUAN}

Stroke saat ini harus dipandang sebagai kedaruratan medis selain serangan jantung. Keterlambatan untuk mendapatkan pertolongan medis dapat meningkatkan jumlah kematian dan kecacatan (Morton, Fontaine, Hudak, \& Gallo, 2012). Data World Health Organization (WHO) tahun 2016 menunjukkan bahwa stroke membunuh satu orang setiap enam detik di dunia. Dengan perkiraan setiap tahun 15 juta orang menderita stroke dimana lima juta penderita mengalami kematian dan lima juta penderita stroke lainnya mengalami kecacatan (World Health Organization, 2018).

Data dari Riset Kesehatan Dasar (Riskesdas) tahun 2018 ditemukan prevalensi stroke di Indonesia sebesar 10,9 per 1.000 penduduk. Stroke lebih banyak menyerang pada penderita usia lebih dari 75 tahun 50,2 per 1.000 penduduk, pada jenis kelamin laki-laki 11,0 per 1.000 penduduk, penduduk daerah perkotaan 12,6 per 1.000 penduduk, tidak/belum pernah sekolah 21,2 per 1.000 penduduk dan tidak bekerja 21,8 per 1.000 penduduk (Kementerian Kesehatan Republik Indonesia, 2018). Berdasarkan profil kesehatan provinsi Jawa Tengah tahun 2015, proporsi kasus baru penyakit tidak menular khususnya penyakit stroke sebanyak 2,22\% (Dinas Kesehatan Provinsi Jawa Tengah, 2015).

Besarnya angka kejadian, kematian dan kecacatan akibat stroke secara signifikan meningkatkan beban penyakit dan memperbesar biaya perawatan yang harus dikeluarkan serta meningkatkan beban keluarga. Salah satu upaya yang dilakukan untuk menurunkan beban akibat penyakit stroke adalah meningkatkan outcome dengan memberikan tindakan/penanganan segera setelah serangan stroke serta memberikan

pelayanan yang komprehensif selama perawatan di rumah sakit. Terlambatnya penanganan terhadap kejadian stroke sekitar 83,9\% disebabkan oleh keterlambatan pra rumah sakit. Penyebab pertama keterlambatan sebanyak $62,3 \%$ karena kurangnya pengetahuan keluarga tentang faktor risiko dan peringatan gejala stroke sehingga menyepelekan tanda-tanda dini stroke, keluarga dan penderita berharap gejala dan tanda akan menghilang 2,7\% (Fassbender, Balucani, Walter, Levine, \& Haass, 2013).

Peran keluarga dalam penanganan awal kejadian stroke sangat membantu dalam mengatasi masalah keterlambatan penanganan stroke telah diteliti (Hariyanti, Harsono, \& Prabandari, 2015). Penelitian lain menyatakan bahwa keterlambatan pertolongan pada fase awal harus dihindari dengan pengenalan keluhan dan gejala stroke bagi pasien dan orang terdekat (Duque \& Batalha, 2015). Pengetahuan keluarga tentang stroke dan pengaruhnya pada penanganan pada pasien stroke belum diteliti. Penelitian ini bertujuan untuk mengetahui hubungan antara pengetahuan keluarga dengan perilaku keluarga pada penanganan awal kejadian stroke.

\section{METODE}

Penelitian ini adalah kuantitatif non eksperimental yang menggunakan desain penelitian deskriptif korelasional dengan pendekatan cross-sectional. Penelitian 
dilaksanakan di poli saraf sebuah rumah sakit di Semarang. Sampel penelitian berjumlah 77 orang dengan menggunakan teknik accidental sampling. Kriteria inklusi adalah keluarga pasien stroke iskemik pada serangan pertama, keluarga pasien yang tinggal satu rumah dengan pasien, menagnani pasien saat serangan hingga masuk rumah sakit. Instrumen yang digunakan berupa kuesioner pengetahuan menggunakan modifikasi Stroke Regocnition Questionnaire (SRQ) yang terdiri dari 13 pertanyaan tentang faktor resiko dan 17 pertanyaan tentang gejala awal stroke serta kuesioner perilaku berdasarkan pedoman dari AHA yang terdiri dari 9 pertanyaan. Analisa data yang digunakan pada penelitian ini adalah analisa univariat dan bivariat dengan analisa uji korelasi menggunakan spearman rank dalam bentuk tabel dan persentase.

Etika dalam penelitian dinyatakan dengan ethical clearence yang dikeluarkan oleh FK UNDIP dengan No. 14/EC/KEPK/FK UNDIP/1/2019 dan dinyatakan layak etik pada tanggal 17 Januari 2019.

\section{HASIL}

Tabel 1. Distribusi frekuensi gambaran pengetahuan kelaurga tentang faktor risiko stroke $(n=77)$

\begin{tabular}{clrc}
\hline \multirow{2}{*}{ No } & \multirow{2}{\text{Item}}{\begin{tabular}{c} 
Pernyataan \\
\cline { 2 - 3 }
\end{tabular}} & $\begin{array}{c}\text { Frekuensi } \\
\text { Benar (\%) }\end{array}$ & Salah (\%) \\
\hline 1 & Usia & $36(46,8)$ & $41(53,2)$ \\
\hline 2 & $\begin{array}{l}\text { Olahraga } \\
\text { secara teratur }\end{array}$ & $22(28,6)$ & $55(71,4)$ \\
\hline 3 & Kesulitan tidur & $17(22,1)$ & $60(77,9)$ \\
\hline 4 & $\begin{array}{l}\text { Kekurangan zat } \\
\text { besi }\end{array}$ & $19(24,7)$ & $58(75,3)$ \\
\hline 5 & $\begin{array}{l}\text { Riwayat } \\
\text { keluarga stroke }\end{array}$ & $10(13,0)$ & $67(87)$
\end{tabular}

\begin{tabular}{clcc}
\hline \multirow{2}{*}{ No } & \multicolumn{1}{c}{ Item } & \multicolumn{2}{c}{ Frekuensi } \\
\cline { 2 - 4 } & Pernyataan & Benar (\%) & Salah (\%) \\
\hline 6 & $\begin{array}{l}\text { Kekentalan } \\
\text { darah }\end{array}$ & $35(45,5)$ & $42(54,5)$ \\
\hline 7 & $\begin{array}{l}\text { Tidak bisa } \\
\text { mengejan }\end{array}$ & $21(27,3)$ & $56(72,7)$ \\
\hline
\end{tabular}

Tabel 2. Distribusi Frekuensi Gambaran Pengetahuan tentang Gejala Awal Stroke $(\mathrm{n}=77)$

\begin{tabular}{|c|c|c|c|}
\hline \multirow{2}{*}{ No } & \multirow{2}{*}{$\begin{array}{l}\text { Item } \\
\text { Pernyataan }\end{array}$} & \multicolumn{2}{|c|}{ Frekuensi } \\
\hline & & Benar (\%) & Salah (\%) \\
\hline 1 & $\begin{array}{l}\text { Pusing disertai } \\
\text { mual }\end{array}$ & $38(49,4)$ & $39(50,6)$ \\
\hline 2 & $\begin{array}{l}\text { Kesulitan } \\
\text { bernafas }\end{array}$ & $21(27,3)$ & $56(72,7)$ \\
\hline 3 & $\begin{array}{ll}\text { Dada } & \text { terasa } \\
\text { terbakar }\end{array}$ & $24(31,2)$ & $53(68,8)$ \\
\hline 4 & $\begin{array}{l}\text { Tulisan menjadi } \\
\text { jelek atau } \\
\text { bahkan tidak } \\
\text { bisa dibaca }\end{array}$ & $32(41,6)$ & $45(58,4)$ \\
\hline 5 & $\begin{array}{l}\text { Mendadak } \\
\text { mengalami } \\
\text { kebingungan }\end{array}$ & $23(29,9)$ & $54(70,1)$ \\
\hline 6 & $\begin{array}{l}\text { Penglihatan } \\
\text { pada salah satu } \\
\text { mata atau } \\
\text { keduanya } \\
\text { mendadak } \\
\text { buram }\end{array}$ & $36(46,8)$ & $41(53,2)$ \\
\hline 7 & $\begin{array}{l}\text { Kesulitan } \\
\text { menelan } \\
\text { makanan }\end{array}$ & $25(32,5)$ & $52(67,5)$ \\
\hline 8 & $\begin{array}{l}\text { Tiba-tiba nyeri } \\
\text { pada salah satu } \\
\text { tangan }\end{array}$ & $14(18,2)$ & $63(81,8)$ \\
\hline 9 & $\begin{array}{l}\text { Ketika } \\
\text { makan/minum } \\
\text { sering } \\
\text { berceceran }\end{array}$ & $24(31,2)$ & $53(68,8)$ \\
\hline 10 & $\begin{array}{l}\text { Kemunduran } \\
\text { cara berpikir/ } \\
\text { pelupa ketika } \\
\text { berkomunikasi } \\
\text { dengan orang } \\
\text { lain }\end{array}$ & $18(23,4)$ & $59(76,6)$ \\
\hline 11 & Panas & $21(27,3)$ & $56(72,7)$ \\
\hline
\end{tabular}


Tabel 3. Distribusi frekuensi perilaku keluarga pada penanganan awal stroke $(\mathrm{n}=77)$

\begin{tabular}{clcc}
\hline \multirow{2}{*}{ No } & Item Pernyataan & \multicolumn{2}{c}{ Frekuensi } \\
\cline { 3 - 4 }$(\boldsymbol{\%})$ & $\begin{array}{c}\text { Tidak } \\
(\%)\end{array}$ \\
\hline 1 & $\begin{array}{l}\text { Menilai kelemahan } \\
\text { pasien }\end{array}$ & $5(6,5)$ & $72(93,5)$ \\
\hline & $\begin{array}{l}\text { Pasien segera diantar } \\
\text { ke rumah sakit lebih } \\
\text { dari 3 jam setelah }\end{array}$ & $\begin{array}{c}(20,8) \\
\text { serangan }\end{array}$ & $61(79,2)$ \\
\hline & $\begin{array}{l}\text { Mengatur posisi } \\
\text { kepala (direndahkan } \\
\left.30^{0}\right)\end{array}$ & $\begin{array}{c}16 \\
(20,8)\end{array}$ & $61(79,2)$ \\
\hline 4 & $\begin{array}{l}\text { Menganjurkan pasien } \\
\text { batuk }\end{array}$ & 16 & $61(79,2)$ \\
\hline
\end{tabular}

Tabel 3 menunjukkan bahwa perilaku keluarga pada penanganan awal stroke kurang baik dimana keluarga yang tidak melakukan penilaian pasien dengan metode FAST (Facial drooping, Arm weakness, Speech difficulties and Time) sebanyak 93,5\%, respon segera diantar ke rumah sakit lebih dari 3 jam setelah serangan sebanyak $79,2 \%$, mengatur posisi kepala (direndahkan $30^{\circ}$ ) 79,2\%, menganjurkan pasien batuk sebanyak $79,2 \%$.

Tabel 4. Hubungan pengetahuan keluarga dan perilaku keluarga pada penanganan awal kejadian stroke $(n=77)$

\begin{tabular}{|c|c|c|c|}
\hline \multirow{2}{*}{ Variabel } & Median & \multirow{2}{*}{$p$} & \multirow{2}{*}{$r$} \\
\hline & SD (Min-Max) & & \\
\hline Pengetahuan & $\begin{array}{c}14 \\
2.874(9-23)\end{array}$ & \multirow{2}{*}{0.00} & \multirow{2}{*}{$0.84 *$} \\
\hline Perilaku & $\begin{array}{c}4 \\
1.109(3-7)\end{array}$ & & \\
\hline
\end{tabular}

*Spearman's rho test

Hasil analisis korelasi antara pengetahuan keluarga dengan periku keluarga pada penanganan awal stroke pada Tabel 4 menggunakan uji Spearman Rank menunjukkan nilai p sebesar 0,000 (p $<0,05)$ yang berarti terdapat adanya hubungan antara pengetahuan keluarga tentang faktor risiko dan gejala awal stroke dan perilaku keluarga pada penanganan awal stroke. Kekuatan korelasi antar kedua variabel kuat dan menunjukkan arah korelasi positif $(r=0,839)$. Korelasi dengan arah positif berarti korelasi tersebut searah (semakin besar nilai satu variabel maka semakin besar pula nilai variabel lainnya), artinya semakin tinggi nilai pengetahuan keluarga maka perilaku keluarga juga semakin baik sehingga dapat disimpulkan terdapat hubungan antara pengetahuan keluarga dengan periku keluarga pada penanganan awal stroke.

\section{PEMBAHASAN}

Pengetahuan Keluarga tentang Faktor Risiko dan Gejala Awal Stroke

Hasil penelitian ini menunjukkan bahwa pengetahuan keluarga tentang faktor risiko stroke masih kurang. Handayani tahun 2019 dengan hasil penelitiannya yang menunjukkan bahwa responden yang menjawab dengan benar sangat sedikit (Handayani, 2019). Kurangnya pengetahuan dipengaruhi oleh kurangnya sumber informasi yang diterima oleh keluarga tentang stroke (Susanto, 2012). Informasi tentang faktor risiko, gejala serta penanganan awal stroke bisa didapatkan dari pelayan kesehatan, media sosial (internet, website, facebook, blog, pesan whatsapp dan twitter), maupun media masa (surat kabar, radio dan televisi). Namun pada kenyataannya sumber informasi tersebut masih jarang memberikan informasi tentang pengenalan gejala dan penanganan awal stroke. Pelayan kesehatan harus mengambil peran 
sebagai pemberi informasi (Handayani, 2019). Keberhasilan penanganan stroke akut dimulai dari pengetahuan keluarga bahwa stroke merupakan keadaan gawat darurat. Pendidikan kesehatan diarahkan untuk membantu keluarga melakukan perawatan diri serta bertanggung jawab terhadap kesehatan mereka sendiri dan keluarganya (Beal, 2015; Hafsteinsdóttir, 2011).

\section{Perilaku Keluarga pada Penanganan Awal Stroke}

Hasil penelitian ini menunjukkan bahwa perilaku keluarga kurang baik pada penanganan awal stroke sebanyak 58,44\%. Dapat dilihat dari keluarga yang tidak melakukan penilaian pasien dengan metode FAST sebanyak 93,5\%. Keluarga diharapkan memilikii kesadaran untuk segera membawa pasien ke rumah sakit bila menemukan gejala stroke dengan menggunakan metode FAST (Powers et al., 2015). Namun pada kenyataannya penilaian stroke menggunakan metode FAST belum dilakukan oleh sebagian besar masyarakat. Informasi dari petugas kesehatan atau media sosial masih sangat kurang kepada masyarakat tentang pengenalan gejala awal dan penanganan awal stroke dirumah (Beal, 2015).

Penelitian ini menunjukkan hasil perilaku keluarga pada penanganan awal stroke kurang baik dimana respon segera diantar ke rumah sakit lebih dari 3 jam setelah serangan $79,2 \%$. Sejalan dengan penelitian yang dilakukan Batubara yang menjelaskan bahwa penanganan di rumah terbanyak adalah penanganan kurang baik sebesar 63,3\% (Batubara \& Tat, 2015). Penanganan dini yang paling direkomendasikan untuk stroke diberikan dalam rentang waktu kurang dari tiga jam (golden hour) setelah terjadinya serangan stroke (Rahmina, \& Wahid, 2017). Kewaspadaan terhadap stroke dengan pengenalan cepat terhadap tanda-tanda stroke sangat diperlukan karena sebagian besar (95\%) keluhan pertama serangan stroke terjadi di rumah atau luar rumah sakit. Keterlambatan pertolongan pada fase prehospital harus dihindari dengan pengenalan keluhan dan gejala stroke bagi pasien/orang terdekat serta kecepatan membawa pasien stroke ke rumah sakit untuk mendapatkan penanganan segera (Jauch et al., 2013).

\section{Hubungan Pengetahuan Keluarga dan Perilaku Keluarga pada Penanganan Awal Kejadian Stroke}

Berdasarkan pengujian menggunakan uji spearman rank menunjukkan nilai $\mathrm{p}$ sebesar 0,000 ( $\mathrm{p}<0,05)$. Korelasi antar kedua variabel kuat dan arah korelasi positif $(r=0,839)$. Hal ini menunjukkan terdapat hubungan antara pengetahuan keluarga dengan periku keluarga pada penanganan awal kejadian stroke. Perilaku yang didasari oleh pengetahuan akan lebih langgeng dari pada perilaku yang tidak didasari pengetahuan (Susanto, 2012). Hasil penelitian ini menunjukkan bahwa semakin baik pengetahuan keluarga tentang faktor risiko dan gejala stoke maka keluarga akan segera merespon/menilai suatu stimulus/objek yang berupa faktor risiko dan gejala stroke dengan segera membawa pasien ke rumah sakit/mencari bantuan kesehatan (Jauch et al., 2015). Jika keluarga mempunyai pengetahuan yang baik tentang faktor risiko dan peringatan gejala stroke akan menggunakan pengetahuan tersebut sebagai dasar terbentuknya tindakan dengan segera mengantar pasien ke rumah sakit (Rachmawati, Andarini, \& Ningsih, 2017). Penelitian yang dilakukan Rahmina 
menyatakan bahwa seseorang yang mempunyai pengetahuan yang kurang tentang faktor risiko, peringatan gejala stroke dan ketidak pahaman tentang konsep "time is brain" akan terlambat dalam merespon stroke sebagai kondisi gawat darurat yang harus memerlukan penanganan segera sehingga semakin memperlambat kedatangan ke rumah sakit/mencari bantuan kesehatan (Rahmina, \& Wahid, 2017). Keluarga yang tidak segera membawa pasien stroke ke rumah sakit $\leq 3$ jam disebut dengan berperilaku buruk (Hariyanti et al., 2015).

Kelemahan dari penelitian ini adalah tidak melibatkan faktor lain yang dapat mempengaruhi perliaku keluarga pada penanganan awal kejadian stroke. Namun, penelitian ini memberi gambaran yang kuat tentang hubungan dan arah hubungan antara pengetahuan dan perliaku keluarga pada penanganan awal kejadian stroke. Penelitian selanjutnya diharapkan melibatkan faktor lain yang dapat mempengaruhi perliaku keluarga pada penanganan awal kejadian stroke.

\section{KESIMPULAN DAN SARAN}

Penelitian ini menunjukkan bahwa terdapat hubungan antara pengetahuan dan perilaku keluarga pada penanganan awal kejadian stroke dengan kekuatan korelasi antar kedua variabel kuat dan menunjukkan arah korelasi positif dimana semakin tinggi pengetahuan maka semakin baik perilaku keluarga.

Bagi keluarga dan masyarakat meningkatkan kesadaran untuk segera membawa pasien ke rumah sakit, karena gold period untuk penanganan pasien stroke adalah 3 jam dan time is brain. Keluarga disarankan meningkatkan pengetahuan dengan cara aktif mencari informasi melalui petugas kesehatan dan sarana informasi lain berupa koran, televisi, radio maupun media sosial mengenai kesehatan terutama penyakit stroke, sehingga dapat mengenali dan mengetahui lebih luas tentang faktor risiko, gejala awal, dan cara penanganan penyakit stroke.

Bagi Pelayanan Kesehatan agar memberikan edukasi deteksi dini Pre Hospital dengan metode FAST, pengendalian faktor risiko dan modifikasi gaya hidup, sehingga masyarakat dapat mengetahui bagaimana cara penanganan dini pasca kejadian stroke di rumah dan derajat kecacatan dapat ditekan serendah mungkin serta kualitas hidup dapat ditingkatkan.

\section{DAFTAR PUSTAKA}

Batubara, S. ., \& Tat, F. (2015). Hubungan antara penaganan awal dan kerusakan neurologis pasien stroke di RSUD Kupang. Jurnal Keperawatan Soedirman, 10(3), 143-157. Diperoleh dari http://jks.fikes.unsoed.ac.id/index.ph $\mathrm{p} / \mathrm{jks} /$ article/view/185/86gmbran

Beal, C. C. (2015). Stroke Education Needs of African American Women. Public Health Nursing, 32(1), 24-33. doi: 10.1111/phn.12158

Dinas Kesehatan Provinsi Jawa Tengah (2015). Profil dinas kesehatan provinsi Jawa Tengah 2012 \& 2013. Semarang.

Duque, A. S., \& Batalha, V. (2015). Awareness of stroke risk factors and warning signs and attitude to acute stroke. International Archives of Medicine, 8(195), 1-18. doi: $10.3823 / 1794$ 
Fassbender, K., Balucani, K., Walter, S., Levine, S., \& Haass, A., \& Grotta J. (2013). Streamlining of prehospital stroke management: The golden hour. Lancet Neuro, 12, 585-596.

Hafsteinsdóttir, T. B., Vergunst, M., Lindeman, E., \& Schuurmans, M. (2011). Educational needs of patients with a stroke and their caregivers: a systematic review of the literature. Patient Education and Counseling, 85(1), 14-25. doi:10.1016/j.pec.2010.07.046

Handayani, F. (2019). Pengetahuan tentang stroke, faktor risiko, tanda peringatan stroke dan respon mencari bantuan pada pasien stroke iskemik. Jurnal Ilmu Keperawatan Medikal Bedah, 2(2), $12 . \quad$ doi: 10.32584/jikmb.v2i2.406

Hariyanti, T., Harsono, \& Prabandari, Y. S. (2015). Health seeking behaviour pada pasien stroke. Universitas Brawijaya Malang, 28(3), 242-246. doi: 10.21776/ub.jkb.2015.028.03.15

Jauch, E. C., Saver, J. L., Adams, H. P., Bruno, A., Connors, J. J. B., Demaerschalk, B. M., ... Yonas, H. (2013). Guidelines for the early management of patients with acute ischemic stroke: A guideline for healthcare professionals from the American Heart Association/American Stroke Association. Stroke, 44(3), 870-947. doi:

10.1161/STR.0b013e318284056a

Kementerian Kesehatan Republik Indonesia. (2018). Profil Kesehatan Indonesia. Jakarta.
Morton, P., Fontaine, D., Hudak, C., \& Gallo, B. (2012). Keperawatan kritis. (N. Subekti, E. Yudha, D. Yulianti, Nurwahyu, \& R. Kapoh, Eds.) (8th ed.). Jakarta: EGC.

Powers, W. J., Derdeyn, C. P., Biller, J., Coffey, C. S., Hoh, B. L., Jauch, E. C., ... Meschia, J. F. (2015). 2015 American Heart Association/American Stroke Association focused update of the 2013 guidelines for the early management of patients with acute ischemic stroke regarding endovascular treatment: A guideline for healthcare professionals from the American Heart Association/American Stroke Association. Stroke, 6(10), 3020-35. doi:

10.1161/STR.0000000000000074

Rachmawati, D., Andarini, S., \& Ningsih, D. K. (2017). Pengetahuan keluarga berperan terhadap keterlambatan kedatangan pasien stroke iskemik akut di instalasi gawat darurat. Jurnal Kedokteran Brawijaya, 29(4), 369-376. doi: 10.21776/ub.jkb.2017.029.04.15

Rahmina Y., Wahid A., A. R. (2017). Tingkat pendidikan keluarga terhadap golden hour pasien stroke di RSUD Ulin Banjarmasin, 5(1), 6877.

Susanto, T. (2012). Buku ajar keperawatan keluarga: Aplikasi teori pada praktik asuhan keperawatan keluarga. Jakarta: TIM.

World Health Organization. (2018). The top 10 causes of death. Diperoleh 
dari

http://www.who.int/mediacentre/fact

sheets/fs310/en/ 